\title{
Two Suturing Approaches with Punch Trabeculectomy: A Prospective Randomized study
}

\author{
Khaled Hamdi Elbaklish \\ Assistant Prof in Ophthalmology Department \\ Ain Shams University \\ Cairo Egypt \\ khaled.hamdy62@yahoo.com
}

DOI: 10.31364/SCIRJ/v9.i02.2021.P0221840

http://dx.doi.org/10.31364/SCIRJ/v9.i02.2021.P0221840

\begin{abstract}
Two Suturing Approaches with Punch Trabeculectomy: A Prospective Randomized study
\end{abstract}

Aims: To evaluate the outcomes of punch trabeculectomy with two different suturing methods (tight versus loose nonreleasable apical suture with additional releasable sutures as needed).

Methods: Eighty Patients with uncontrolled glaucoma and their ages were between 40 and 60 years. Participants were inclusive, randomly distributed for tight non-releasable apical suture technique group (group A- forty patients) and secure/loose suture at the apex of the triangular scleral flap technique group (group B-forty patients). During trabeculectomy, we used two releasable stitches at the sides of the flap in group A and two-four releasable stitches at the sides of the flap in group B.

Results: The mean preop-IOP with treatment was $21.17 \mathrm{mmHg}$ in group A and $21.02 \mathrm{mmHg}$ in group B. In group $\mathrm{A}$, the mean IOP was $17.9 \mathrm{mmHg} \pm 3.57$ (range24-13 $\mathrm{mmHg}$ ), and $14.82 \mathrm{mmHg} \pm 1.86$ (range $19-12 \mathrm{mmHg}$ ) in group $\mathrm{B}$ at one year follow up. (p<.000) All measurements of IOP in both groups were statistically reduced compared with the baseline IOP $(\mathrm{P}<.000)$. In survival analysis there was significant difference in time to raise IOP and starting glaucoma medication $(\mathrm{P}=.005)$. Flat bleb $(40 \%)$, encysted bleb $(15 \%)$, and diffuse bleb (45\%) reported in group A versus flat bleb $(10 \%)$, encysted bleb $(2.5 \%)$, and diffuse bleb $(87.5 \%)$ reported in group B. Needling procedure was done for eight cases in group A. Transient hypotony reported in 3 eyes $(7.5 \%)$ in group B.

Conclusion: Comparing two different trabeculectomy suturing methods (tight vs. loose non-releasable apical suture with additional releasable sutures as needed, we found good controlling of IOP, limited number of glaucoma medications and diffuse bleb in $87.5 \%$ of cases of secure/loose suture at the apex of the triangular scleral flap. The tight non-releasable apical suture may be the source of $40 \%$ flat bleb and $15 \%$ encysted bleb in group A.
Key words: glaucoma- trabeculectomy -releasable -tightsuture

\section{Introduction}

Trabeculectomy is still used as the main surgical procedure in glaucoma for over 40 years. Despite that, there is incidence of postoperative complications with this procedure. ${ }^{1}$ Punch trabeculectomy (PT) has a good reputation, can adjust the surgical efficiency and minimize complications. ${ }^{2-6}$

In trabeculectomy, the scleral flap sutures should allow aqueous leakage without postoperative hypotony. The flap can be sutured tightly and laser suturelysis can be used later. ${ }^{7,8}$

Laser suture lysis can be used and lower IOP, despite that; it can cause conjunctival burn, inflammation, conjunctival scars and flat bleb.

Releasable sutures are alternative method to close the scleral flap with slipknots that can be removed postoperatively without laser suturelysis. ${ }^{10,11}$

Trabeculectomy was done with releasable sutures in randomized trials however, these studies have small sample size and results were not satisfactory. ${ }^{12,13}$

In this study, we have two kinds of scleral flap suturing in trabeculectomy procedure. One group with tight suture at the apex of the triangular scleral flap (group A- control group) and a secure/loose suture at the apex of the triangular scleral flap in group B (group B- experimental group) and additional releasable sutures as needed.

Patients and Methods

This study was approved by the Ethics Committee of Ain Shams University (registration number: FWA 000017585, FMASU R23/2017) and we obtained written informed consent according to Declaration of Helsinki.

This is a prospective randomized study. Eighty patients had uncontrolled glaucoma, enrolled in this clinical trial and randomized to tight flap technique group (group A) and loose flap technique group (group B). Randomization assigned 40 patients to group A and 40 patients to group B. Punch trabeculectomy was performed in eye centers and Ain Shams Specialized Hospital between 2012 and 2016.

The inclusion criteria involved patients with uncontrolled primary open-angle glaucoma, pigmentary or psuedoexfoliative glaucoma on antiglaucoma medication. The maximum tolerated glaucoma treatment was including acetazolamide tablets. Pseudophakic eyes were included. 
We excluded those patients with high risk factors for failed trabeculectomy, e.g. previous failed trabeculectomy surgery and active intraocular infection/ inflammation. Patients with aphakic eyes were excluded. Patients with previous ocular incisional surgery (except for clear cornea cataract

Surgery) were excluded.

The participants were masked during study time through permuted variable block randomization scheme. Only 1 eye of each patient was eligible for enrollment. Details of study patients, eligibility, and patients following the study protocol were received, edited, processed, analyzed, and stored. The corrected visual acuity of these cases was measured in both groups. Details of slit lamp, angle, optic disc and retinal examination for both groups were collected. Visual field examination and OCT were implemented in all participants.

Punch Trabeculectomy
The surgical procedure was performed by the author (Khaled Hamdi). The same surgical steps were followed in all eyes: Eighty patients underwent trabeculectomy, divided into two equal groups (forty cases-forty cases). All patients were given a peribulbar injection of Lignocaine $2 \%$ and Marcaine $0.5 \%$ with Hyaluronidase 15 units $/ \mathrm{ml}$. Superior rectus traction suture, limbal based conjunctival flap. The conjunctival and Tenon's capsule was careful dissected using blunt scissors. The triangular scleral flap had 3-mm sides and dissected deeply with flap thickness $50 \%$ of sclera thickness using superblade straight $30^{\circ}(\mathrm{MST} 30)$ and crescent knife beveled up (MCU26) . Microsurgical sponges saturated with Mitomycin- C $(0.2 \mathrm{mg} / \mathrm{mL})$ were placed in the scleral surface and covered with Tenon's capsule/conjunctival flap for 2 minutes. Then the sponges were removed, and the area was copiously irrigated with BSS solution. A paracentesis was made with superblade straight $30^{\circ}$ (MST30) either at the 3:00 or 9:00 o'clock position. The central part of the flap was dissected 1-2 mm into clear cornea. Sclerostomy was done with the kelly scleral punch $1.0 \mathrm{~mm}$ (2286-10 Teufel) 3-5 bites to remove $1 / 2-2 / 3$ of trabecular meshwork and scleral lamellae area and create opening equaled to $60 \%-70 \%$ of the scleral bed under the scleral flap. The punch should be aligned perpendicularly to ensure a clean non- shelved sclerostomy. An iridectomy was made slightly wider than the opening of the sclerostomy in all patients. In group A, a tight, nonreleasable apical suture was placed at the apex of the scleral flap (this suture was associated with moderate aqueous flow from both sides of the triangle and near edge to edge approximation at the sides). Next, 2 releasable sutures were placed at the sides of the scleral flap as depicted in figure 1.

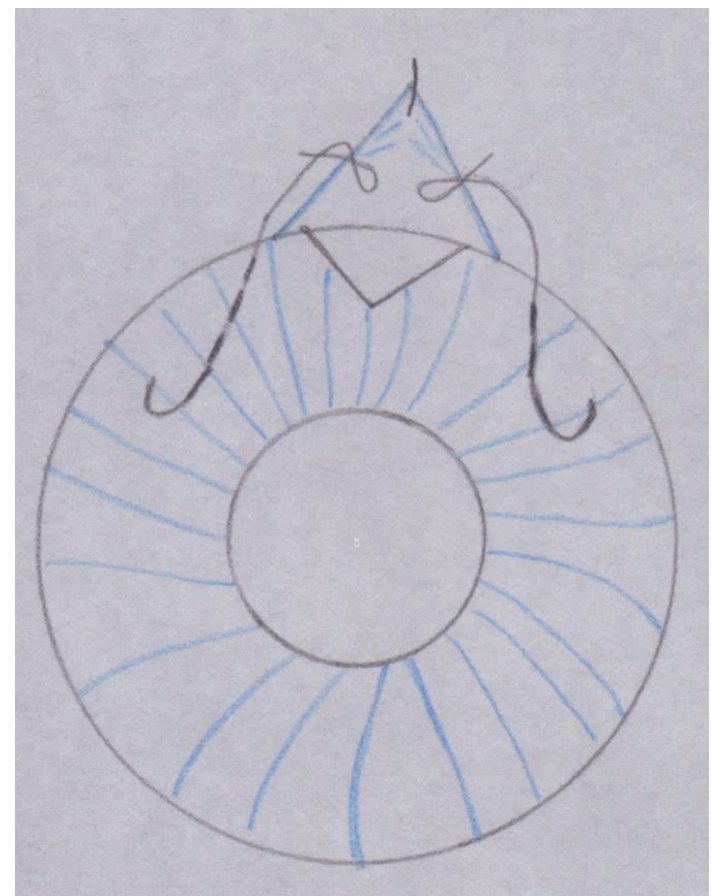

Fig-1 Triangular scleral flap is closed with one tight and permanent suture at apex and one releasable suture on each side in group $\mathrm{A}$. 
We chose to use 4-throw releasable sutures. In group B, a loose / securing, non-releasable apical suture was placed at the apex of the scleral flap (this suture was associated with a lot of aqueous flow from both sides of the triangle and the edges of the triangular sides were loose). Next, 2-4 releasable sutures were placed at the sides of the scleral flap as depicted in figure 2 .

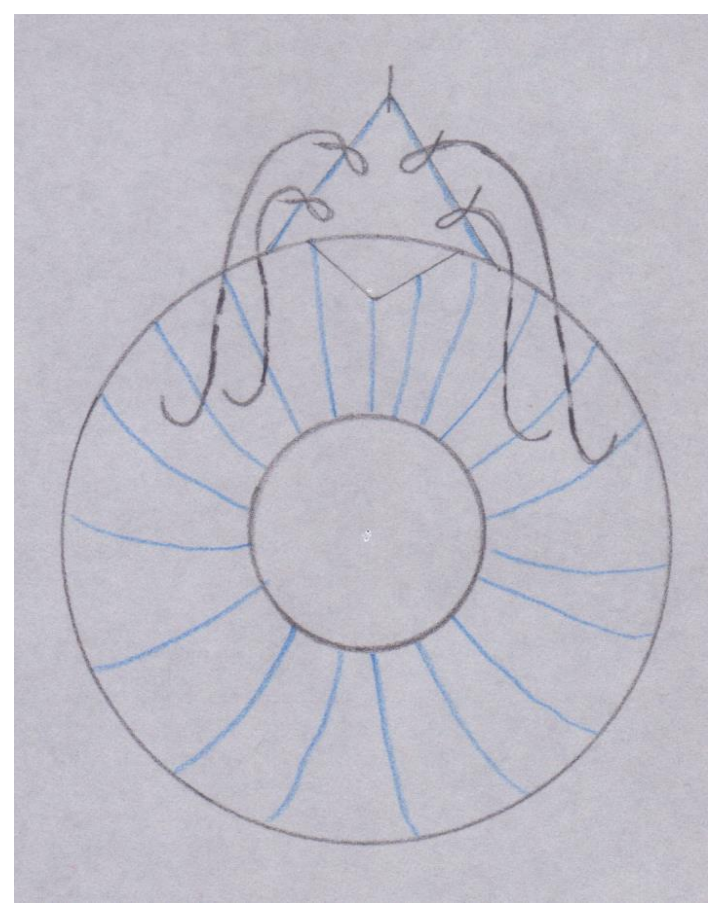

Fig-2 Triangular scleral flap is closed with one securing and permanent suture at apex and two releasable sutures on each side in group B.

The releasable sutures should be tight in slipknot fashion. The leakage was tested by Weck-Cel sponge at both sides of the triangle. We were testing the amount of leakage through reformation of the $\mathrm{AC}$ with $\mathrm{BSS}$ solution, and titrate the amount of leakage at the edges of sclera flap. Each side of the triangle should have minimal flow (slow ooze) at the end. Closure of the conjunctival incision with 10/0 interrupted stitches. Subconjunctival Dexamethasone / gentamycin were injected.

Post-operative Care
Topical ofloxacin and prednisolone eye drops were prescribed with gradual reduction in frequency. One week after, removal of conjunctival sutures was done. Two to three weeks later, removal of releasable sutures was starting. We removed the first releasable suture when the anterior chamber was deep and intraocular pressure reached $>16 \mathrm{~mm} \mathrm{Hg}$. Releasable suture removal usually produced an immediate increase in filtration with enlargement of the filtering bleb and a fall in intraocular pressure.

The second suture was removed one to several days later. The releasable sutures removal was done in the clinic under topical anesthesia. With slit lamp magnification, we used McPherson forceps for suture removal. There was close follow up in the first two months. The interval between the visits will be several days or one week till complete removal of releasable sutures. After that, the follow up will be regular (every month) till the end of the study.

\section{Statistical Methods}

Demographic data of the participants were estimated with Mann-Whitney, independent T-test and chi-square test of independence.

The primary outcome measure was surgical success defined as IOP range was between $6 \mathrm{mmHg}-16 \mathrm{mmHg}$ without medication and guarded success (IOP range was between $6 \mathrm{mmHg}-16 \mathrm{mmHg}$ with medication). Failure was established when the IOP was outside the success range on two consecutive visits (above $16 \mathrm{mmHg}$ or below $6 \mathrm{mmHg}$ despite the medication). The two groups were compared by linear regression, and general linear model (GLM) multivariate analysis and independent T-test.

The second outcome measure was bleb morphology, the bleb features were height, extent, vascularity, and leakage. So, we commented on the bleb features on each patient in study groups as grade- 1 high elevated bleb, grade- 2 low elevated bleb, grade-3-encysted bleb, grade-4 flat bleb. Chi-square test of independence was used for Sub-group analysis. The third outcome measures were the visual acuity changes, progression of visual field, intraoperative complications, and postoperative complications after surgery.

Kaplan-Meier survival analysis was applied to assess oneyear success rates.

G*Power was used to estimate the sample size considering a study power at 0.8 with $\propto$ of 0.05 aiming to detect at least difference of $3-4 \mathrm{mmHg}$ in mean IOP in the 12 postoperative months, and assuming $\mathrm{SD}$ of $3 \mathrm{mmHg}$ between the two groups. The overall study size of 80 cases can allow $5 \%$ dropout rate. ${ }^{14}$

Results

Eighty participants involved in the sample. The ages of the participants varied between 40 and 60 years (the mean age was 49.85 years \pm 6.14 for group A and 49.5 years \pm 6.06 for group B). Twenty-two patients $(55 \%)$ were females and eighteen patients $(45 \%)$ were males in group A, twenty-five patients $(62.5 \%)$ were females, and fifteen patients $(37.5 \%)$ were males in group B. In 
group A, twenty-five patients $(62.5 \%)$ were hypertensive, and fifteen patients $(37.5 \%)$ were diabetic. Thirty patients $(75 \%)$ were hypertensive and twelve patients $(30 \%)$ were diabetic in group B. These participants had different kinds of scotomas in visual field testing like double arcuate scotoma, nasal step, concentric contraction and tubular field. The participants had no history of glaucoma surgeries or laser sessions. The demographic data of patients were recording in table-1.

\begin{tabular}{|c|c|c|c|}
\hline & $\begin{array}{l}\text { Group-A } \\
\text { patients }\end{array}$ & Group-B patients & $\begin{array}{c}\text { P- } \\
\text { value }\end{array}$ \\
\hline $\begin{array}{r}\text { Sex-females } \\
\text { males }\end{array}$ & $\begin{array}{l}22 \\
18\end{array}$ & $\begin{array}{l}25 \\
15\end{array}$ & $\begin{array}{l}.317 \\
.231\end{array}$ \\
\hline $\begin{array}{l}\text { Ages } \\
\text { Range } \\
\text { Mean age }\end{array}$ & $\begin{array}{l}40-60 \\
49.85 \pm 6.14 \mathrm{SD}\end{array}$ & $\begin{array}{c}40-60 \\
49.5 \pm 6.06 \mathrm{SD}\end{array}$ & .911 \\
\hline $\begin{array}{l}\text { Systemic } \\
\text { diseases } \\
\text { Hypertension } \\
\quad \text { DM }\end{array}$ & $\begin{array}{l}25 \\
15\end{array}$ & $\begin{array}{l}30 \\
12\end{array}$ & $\begin{array}{l}.144 \\
.272\end{array}$ \\
\hline $\begin{array}{l}\text { Angle of } \\
\mathrm{AC}\end{array}$ & Open & Open & \\
\hline Visual acuity & $6 / 6-6 / 24$ & $6 / 6-6 / 36$ & .436 \\
\hline $\begin{array}{l}\text { IOP } \\
\text { Range } \\
\text { Mean } \\
\text { Range of } \\
\text { IOP under } \\
\text { treatment } \\
\text { Mean }\end{array}$ & $\begin{array}{l}\quad 27-43 \mathrm{mmHg} \\
35.67 \mathrm{mmHg} \\
\pm 4.36 \\
\\
\quad 17-28 \mathrm{mmHg} \\
\\
21.17 \mathrm{mmHg} \pm \\
3.11 \mathrm{SD}\end{array}$ & $\begin{array}{l}27-42 \mathrm{mmHg} \\
35.10 \mathrm{mmHg} \pm 5.05 \\
17-28 \mathrm{mmHg} \\
21.02 \mathrm{mmHg} \pm 3.66 \\
\text { SD }\end{array}$ & $\begin{array}{l}.409 \\
.390\end{array}$ \\
\hline $\mathrm{C} / \mathrm{D}$ ratio & $0.7-0.9$ & $0.7-0.9$ & \\
\hline $\begin{array}{l}\text { Visual field } \\
\text { changes }\end{array}$ & \begin{tabular}{l}
\multicolumn{1}{c}{ double } \\
arcuate \\
scotoma, nasal \\
step, concentric \\
contraction and \\
tubular field
\end{tabular} & $\begin{array}{l}\text { double arcuate } \\
\text { scotoma, nasal } \\
\text { step, concentric } \\
\text { contraction and } \\
\text { tubular field }\end{array}$ & \\
\hline $\begin{array}{l}\text { Treatment } \\
\text { given to } \\
\text { patients }\end{array}$ & \# of meds & \# of meds & \\
\hline
\end{tabular}

The mean IOP (baseline /preoperative IOP) was $35.67 \mathrm{mmHg}$ in group $\mathrm{A}$ and $35.1 \mathrm{mmHg}$ in group B. Preoperative IOP with treatment was $21.17 \pm 3.11 \mathrm{~mm}$ $\mathrm{Hg}$ in group $\mathrm{A}$, and $21.02 \pm 3.66 \mathrm{~mm} \mathrm{Hg}$ in group $\mathrm{B}$. After surgery, all measurements of IOP in both groups were statistically reduced compared with the baseline IOP $(\mathrm{P}<.000)$. Figure -3 and table-2 show the mean IOPs at various time points in one-year follow up in both groups.

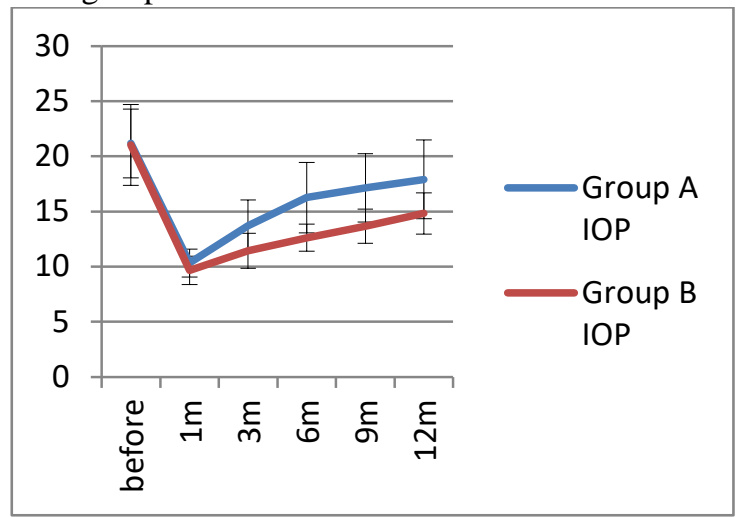

Fig 3- Intraocular pressure measurements (preop IOP with treatment and postop IOP) were recorded during one-year follow-up in both groups. In group A, the blue curve will rise again while the sloping of group B curve (red curve) has reduced height. The curves illustrate mean values as the center and standard deviation as the upper and lower lines.

\begin{tabular}{|c|c|c|c|}
\hline $\begin{array}{l}\text { IOP } \\
(\mathrm{mmHg} ; \\
\text { mean } \pm \mathrm{SD}) \\
+ \text { Glaucoma } \\
\text { Medication } \\
\text { +success } \\
\text { and } \\
\text { qualified } \\
\text { success }\end{array}$ & $\begin{array}{l}\text { group A patients } \\
\text { (40 cases) }\end{array}$ & $\begin{array}{l}\text { group B patients } \\
\text { (40 cases) }\end{array}$ & P- Value \\
\hline $\begin{array}{l}\text { Preoperative } \\
\text { IOP }\end{array}$ & $\begin{array}{l}35.67 \mathrm{mmHg} \pm 4.36 \\
\mathrm{SD} \\
(27-43 \mathrm{mmHg})\end{array}$ & $\begin{array}{l}35.1 \quad \mathrm{mmHg} \\
\pm 5.05 \quad \mathrm{SD} \quad(27- \\
43 \mathrm{mmHg})\end{array}$ & .409 \\
\hline $\begin{array}{l}\text { Preoperative } \\
\text { IOP with } \\
\text { medication }\end{array}$ & $\begin{array}{l}21.17 \mathrm{mmHg} \pm 3.11 \\
\mathrm{SD}\end{array}$ & $21.02 \mathrm{mmHg} \pm 3.6$ & .390 \\
\hline $\begin{array}{l}\text { Glaucoma } \\
\text { medications }\end{array}$ & $\begin{array}{l}(17-28 \mathrm{mmHg}) \\
3.90 \pm 0.33\end{array}$ & $\begin{array}{l}6 \quad \mathrm{SD}(17-28 \\
\mathrm{mmHg}) \\
3.85 \pm 0.40\end{array}$ & .98 \\
\hline $\begin{array}{l}\text { Mean } \\
\text { postop IOP } \\
(\mathrm{mmHg}) \text { at } \\
\text { first month } \\
\text { Complete } \\
\text { success }\end{array}$ & $\begin{array}{l}10.32 \mathrm{mmHg} \pm \\
1.26(12-8 \mathrm{mmHg} \\
\text { with } 11 \mathrm{~mm} \mathrm{Hg} \pm 2 \\
\text { IOP drop) } \\
\text { (40 cases) }\end{array}$ & $\begin{array}{lr}9.65 & \mathrm{mmHg} \\
\pm 1.29 \quad(12-8 \\
\mathrm{mmHg} \text { with12 } \\
\mathrm{mm} \mathrm{Hg} \pm 2 \text { IOP } \\
\text { drop) } \\
\text { (40 cases) }\end{array}$ & .021 \\
\hline $\begin{array}{l}\text { Qualified } \\
\text { success } \\
\text { Glaucoma } \\
\text { medications }\end{array}$ & $\begin{array}{l}(0.00 \text { cases }) \\
(0.00 \text { cases })\end{array}$ & $\begin{array}{l}(0.00 \text { cases }) \\
(0.00 \text { cases })\end{array}$ & \\
\hline $\begin{array}{l}\text { Mean postop } \\
\text { IOP (mmHg) at } \\
\text { three month }\end{array}$ & $\begin{array}{l}13.7 \mathrm{mmHg} \pm 2.33 \\
(19-10 \mathrm{mmHg} \text { with } 8 \\
\mathrm{mm} \mathrm{Hg} \pm 1 \text { IOP drop })\end{array}$ & $\begin{array}{l}11.42 \mathrm{mmHg} \pm 1.59 \\
\text { (range } 14-9 \mathrm{mmHg} \\
\text { with10 } \mathrm{mm} \mathrm{Hg} \pm 1.5 \\
\text { IOP drop) }\end{array}$ & $<.000$ \\
\hline $\begin{array}{l}\text { Complete } \\
\text { success }\end{array}$ & (36 cases) & (40 cases) & \\
\hline
\end{tabular}




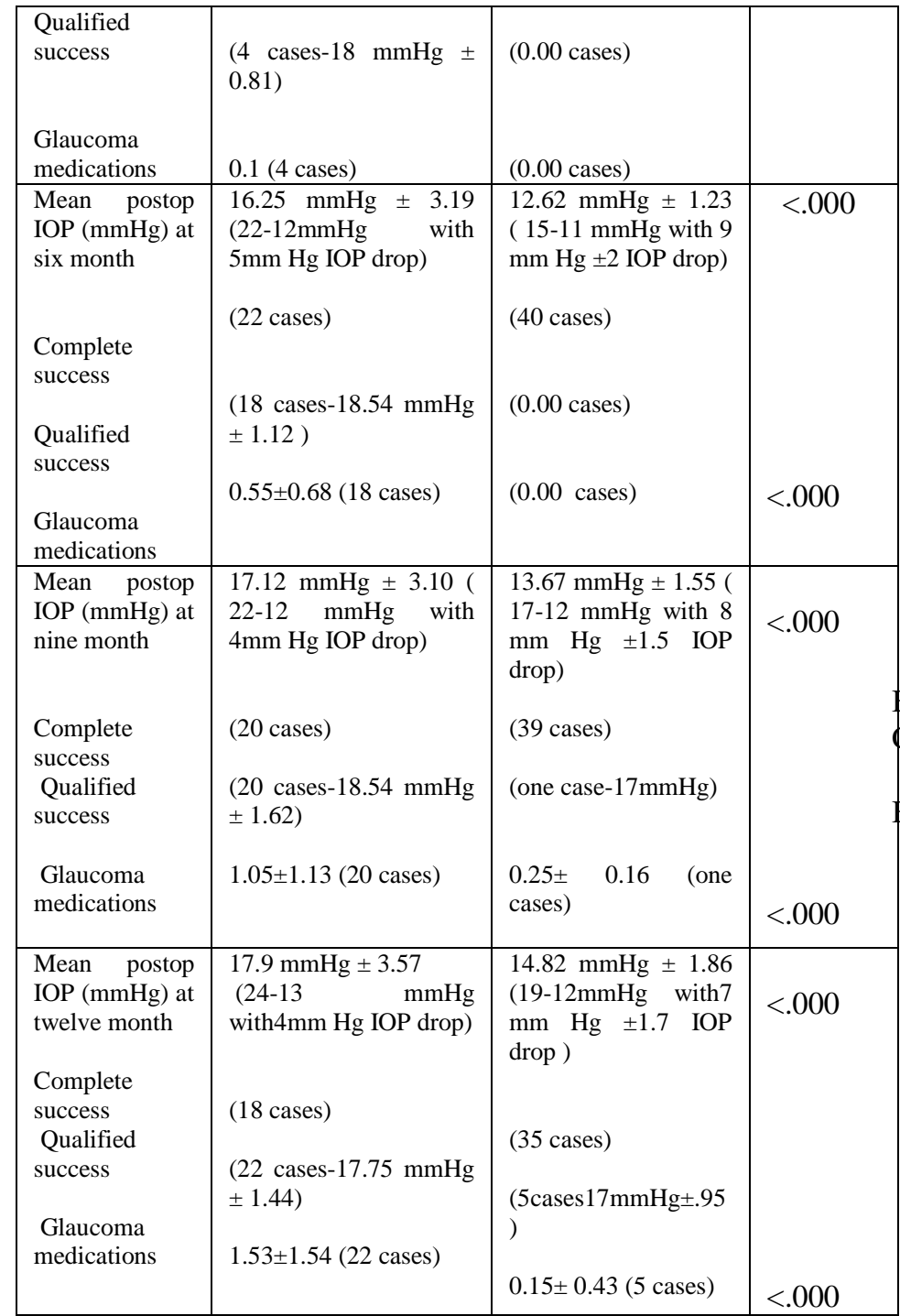

Table-2 Intraocular pressure, medical therapy and treatment outcomes at baseline and Follow-up in group A (tight suture at the apex of the triangular scleral flap) and group B (a secure/loose suture at the apex of the triangular scleral flap).

One year after surgery, IOP was $17.9 \mathrm{mmHg} \pm 3.57$ in group $\mathrm{A}$, and $14.82 \mathrm{mmHg} \pm 1.86$ in group $\mathrm{B}$. $(\mathrm{p}<.000)$ The mean number of glaucoma medications in the group A was reduced from $3.90 \pm 0.33$ at baseline to1.53 $\pm 1.54(\mathrm{P}<0.000)$ at the final one-year follow-up visit versus group $B$, the mean number of glaucoma medications was reduced from $3.85 \pm 0.40$ at baseline to $0.15 \pm 0.43(\mathrm{P}<0.000)$. At 12 months, the success rates in both groups were $18 / 40$ (45\%) in group A and 35/40 $(87.5 \%)$ in group B. Participants with qualified success, were $22 / 40(55 \%)$ in group $\mathrm{A}$ and $5 / 40$ $(12.5 \%)$ in group B. $(\mathrm{P}<0.000)$ Kaplan Meier analysis comparing the cumulative probability of failure (time to raise IOP and starting glaucoma medication) at oneyears showed that group A had cumulative failure $(\mathrm{P}<$ 0.005) (Fig 4).

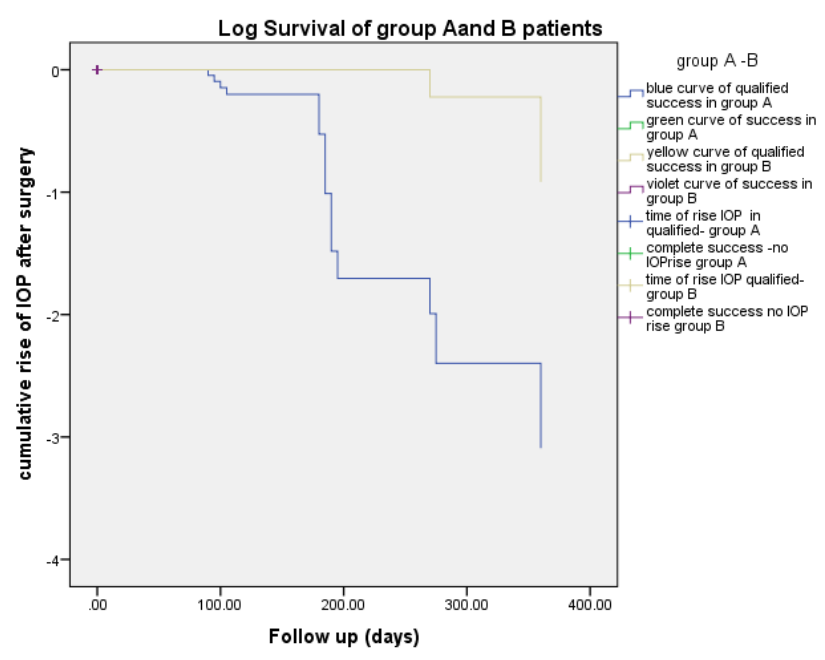

Fig -4 Kaplan-Meier survival analysis of both groups A and $\beta$ using the time of rising IOP as the primary outcome criteria. Censoring is denoted by hash marks.

\section{Bleb Morphology}

After trabeculectomy, the bleb extended from 1 to 4 clock hours. In group A, sixteen cases (40\%) had flat bleb (type4), six cases (15\%) had encysted bleb (type-3) fourteen cases (35\%) had low diffused bleb (type-2) and four cases $(10 \%)$ had high diffuse bleb (type-1). The diffuse bleb in thirty-five cases $(87.5 \%)$ of group B involved low diffuse (type-2) in seventeen cases $(42.5 \%)$, and moderate elevated bleb (type-1) in eighteen cases $(45 \%, \mathrm{P}<.000)$. The bleb was flat (type-4, $\mathrm{P}<.000)$ in four cases $(10 \%)$ and localized- encysted (type-3, $\mathrm{P}=.008)$ in single case $(2.5 \%)$. The flat bleb was white, avascular, while the elevated, diffuse bleb was grey. The low diffuse bleb seemed to be greyish white and opalescent.

\section{Visual Acuity}

The corrected visual acuity of the participants was between $6 / 6-6 / 24$. One- year follow up, the visual acuity was stable in twenty-five cases in group $\mathrm{A}$, ten cases had one-line deterioration and five cases had one line improvement. In group B thirty-two cases had stable visual acuity, four cases improved one line and four cases had one-line deterioration. In paired t-test no significant changes in visual acuity in both groups when comparing baseline visual acuity with one-year visual acuity. $\mathrm{P}<0.211, \mathrm{P}<0.854$

$\mathrm{T}$ - Independent test revealed no significant changes in visual acuity outcomes between groups $\mathrm{A}$ and $\mathrm{B}$. $\mathrm{P}<0.95$

Visual Fields

Perimetry was stable for one year follow up in twenty-five cases in group A and thirty- five of group B. In fifteen cases of group A and five cases of group B, MD was stable, and PSD rate was progressive (0.028- $0.04 \mathrm{~dB} /$ year). $\mathrm{P}<0.693$ Table-3

\begin{tabular}{|c|c|c|c|}
\hline & Group A & Group B & $\begin{array}{c}\text { P- } \\
\text { value }\end{array}$ \\
\hline $\begin{array}{c}\text { IOP at 12 } \\
\text { months }\end{array}$ & $\begin{array}{l}17.9 \mathrm{mmHg} \pm \\
3.57\end{array}$ & $\begin{array}{l}14.82 \mathrm{mmHg} \pm \\
1.86\end{array}$ & $\mathrm{p}<.000$ \\
\hline $\begin{array}{c}\text { NO of } \\
\text { complete } \\
\text { success people }\end{array}$ & 18 & 35 & $\mathrm{p}<.000$ \\
\hline $\begin{array}{c}\text { NO of } \\
\text { qualified }\end{array}$ & 22 & 5 & \\
\hline
\end{tabular}




\begin{tabular}{|c|c|c|c|}
\hline success people & & & \\
\hline $\begin{array}{c}\text { Number of } \\
\text { medications }\end{array}$ & $\begin{array}{l}\text { Two drugs } \\
\text { (3months after } \\
\text { surgery) }\end{array}$ & \begin{tabular}{l}
\multicolumn{2}{c}{ Two drugs (9 } \\
months after \\
surgery)
\end{tabular} & $\mathrm{P}=.005$ \\
\hline $\begin{array}{l}\text { Visual } \\
\text { acuity } \\
\text { Number with } \\
\text { stable visual } \\
\text { acuity } \\
\text { Number with } \\
\text { one-line } \\
\text { deterioration } \\
\text { Number with } \\
\text { one-line } \\
\text { improvement }\end{array}$ & 10 & 32 & $\mathrm{P}<0.953$ \\
\hline $\begin{array}{l}\text { Bleb } \\
\text { morphology } \\
\text { Number } \\
\text { with flat bleb } \\
\text { Number } \\
\text { with high } \\
\text { diffuse bleb }\end{array}$ & $\begin{array}{l}16 \text { (type-4), } \\
4 \text { had (type-1) }\end{array}$ & $\begin{array}{l}4 \text { (type- } 4) \\
18(\text { type-1) }\end{array}$ & $\mathrm{P}<.000$ \\
\hline $\begin{array}{l}\text { Number } \\
\text { with low } \\
\text { diffuse bleb } \\
\text { Number } \\
\text { with encysted } \\
\text { bleb }\end{array}$ & $\begin{array}{l}14 \text { (type-2) } \\
6 \text { (type-3) }\end{array}$ & $\begin{array}{l}\text { Single case } \\
\text { (type-3) }\end{array}$ & $\begin{array}{l}\mathrm{P}<.000 \\
\mathrm{P}=.008\end{array}$ \\
\hline $\begin{array}{l}\text { Incidence of } \\
\text { postoperative } \\
\text { complications } \\
\text { Hyphema } \\
\text { Needling } \\
\text { procedure } \\
\text { Transient } \\
\text { hypotony }\end{array}$ & $\begin{array}{l}\text { Twelve eyes } \\
\text { Eight cases } \\
\text { - }\end{array}$ & $\begin{array}{l}\text { Five eyes } \\
\text { - } \\
\text { Three eyes }\end{array}$ & \\
\hline $\begin{array}{l}\text { Visual field } \\
\text { changes } \\
\text { Number } \\
\text { with stable } \\
\text { Perimetry } \\
\text { Number } \\
\text { with stable } \\
\text { MD, and PSD } \\
\text { progression. }\end{array}$ & 15 & 35 & $\mathrm{P}<0.693$ \\
\hline
\end{tabular}

Table-3 the postoperative data of group $\mathrm{A}$ and $\mathrm{B}$ patients in one- year follow up.

MD: Mean Deviation PSD: Pattern

Standard Deviation

Surgical Complications and Additional Surgeries

Intraoperative hyphema happened in twelve eyes in group $\mathrm{A}$ and five cases in group B. Needling procedure was done for eight cases in group A. Three eyes $(7.5 \%)$ in group B exhibited hypotony without shallowing $\mathrm{AC}$ in the first month and recovered during the one-year follow up. Table-3

Discussion

The one-year follow- up after punch trabeculectomy with secure/loose suture at the apex of the triangular scleral flap and additional releasable sutures as needed (group B) can give good mean IOP (14.82 mmHg), limited use of glaucoma medications and diffuse bleb in $87.5 \%$ of cases. In the previous studies, the oneyear follow- up gave $\leq 20 \mathrm{~mm} \mathrm{Hg}$ IOP in $90 \%$ of cases with or without medication. ${ }^{15}$ In this trial, the IOP reduction after surgery is limited with $40 \%$ flat bleb and $15 \%$ encysted bleb in group A (tight suture at the apex of the triangular scleral flap with 2 releasable sutures were placed at the sides of the scleral flap). In secure/loose suture technique, the 3-4 releasable sutures are a good number to close the scleral flap effectively. This way of closure can create better aqueous leakage resistance in early postoperative days. The tension in each suture should be just enough to lay the flap edge flat on scleral bed. ${ }^{16} \mathrm{We}$ did comparison between two groups used releasable sutures because we considered releasable sutures now is an integral part of punch trabeculectomy procedure. We have also encouraging results for both groups; there is no visual loss after punch trabeculectomy, MD was stable and limited progression of PSD rate. The rates of MD loss before and after trabeculectomy in different studies were $0.20 \mathrm{~dB} /$ year. $^{17}$

After surgery, aqueous flow resistance is important and related to suture design and flap edge relationship. ${ }^{18}$ If the scleral flap is well constructed, the amount of resistance to bulk flow is largely determined by the apposition of the flap to the underlying sclera adjacent to the sclerostomy, which is determined by the tension of the flap, which is in turn determined by suture position and tension. ${ }^{19}$ Aqueous flow resistance should not be affected with removal of releasable sutures and conjunctival sutures. Long-time follow up and late removal of releasable sutures is better than diagnosis of postoperative hypotony and shallow AC after PT. ${ }^{18}$

Apical suture in triangular flap is the most important suture in closing the scleral flap. It should be tight and argon suture lysis can improve aqueous leakage after surgery. ${ }^{18}$ The tight securing apical suture in 22 participants of group A is not suitable to lower IOP or to have functioning bleb. In secure/loose suture technique (group B), we just secure the apical suture and using multiple releasable sutures to distribute the effective power of flap closure among different sutures. We are using 4-throw releasable sutures because we feel 3 or fewer throws give a less secured suture and can easily be loosened by any minor trauma.

Aqueous leakage is the weak point of glaucoma surgery. Surgeon should escape from early postoperative hypotony and shallow AC. At the same time, the surgery can give good reduction in IOP with reducing aqueous leakage resistance. Another weak point in punch trabeculectomy procedure is the use of intraoperative mitomycin-c. Releasable sutures don't 
affect the success rate or increasing the rate complications of mitomycin-c postoperatively. ${ }^{20}$ The first releasable suture is removed14 days after surgery. So, there is time for sealing scleral and conjunctival incisions. This time lag is associated with low incidence of hypotony and shallow AC.

Loosening of the scleral flap sutures as a result of eye rubbing, other minor trauma, or even spontaneously occurring could have adverse consequences. ${ }^{19}$ The free end of releasable suture is cut flash at corneal surface. There is no potential path for bacterial entry. ${ }^{21}$ Needling and minor complications were few in the study, when compared with other studies findings. ${ }^{22}$

This study presents some limitations. It has a small sample size (80 cases), has a relatively short follow-up time (one- year follow up). ${ }^{23}$ Despite these statistical limitations, punch trabeculectomy with secure/loose suture at the apex of the triangular scleral flap and additional releasable sutures as needed may be novel, Conclusion efficacious.

Comparing two different trabeculectomy suturing methods (tight vs. loose non-releasable apical suture placement with additional releasable sutures as needed, we found good controlling of IOP, limited number of glaucoma medications and diffuse bleb in $87.5 \%$ of cases of secure/loose suture at the apex of the triangular scleral flap. The tight non-releasable apical suture may be the source of $40 \%$ flat bleb and $15 \%$ encysted bleb in group A.

\section{References}

1-Back M: Trabeculectomy for glaucoma. Arch Ophthalmol 1975, 93:1372.

2-Chiselita, D: Non-penetrating deep sclerectomy versus trabeculectomy in primary open-angle glaucoma surgery. Eye 2001; 15: 197-201.

3- Rasouli ,H, Foets ,B, Goethls ,M, et al: Modified phacotrabeculectomy with Crozafon punch. Bull Soc Belge Ophtalmol 1996; 261: 59-63.

4- Raina ,UK, Tuli ,D: Trabeculectomy with releasable sutures: a prospective, randomized pilot study. Arch Ophthalmol 1998, 116:1288-1293.

5- Kolker ,AE, Kass ,MA, Rait ,JL: Trabeculectomy with releasable sutures. Arch Ophthalmol 1994, 112:62-66.

6- Matlach, J, Hoffmann,N, Freiberg ,FJ, etal: Comparative study of trabeculectomy using single sutures versus releasable sutures. Clin Ophthalmol 2012, 6:1019-1027.

7- Lieberman, MF: Suture lysis by laser and goniolens. Am J Ophthalmol 1983; 95:257-258.

8- Hoskin ,GD Jr, Migliazzo, C: Management of failing filtering blebs with the argon laser.Ophthalmic Surg 1984; 15:731-733.
9- L'Esperance FJ: The ocular histopathologic effect of krypton and argon laser radiation. Am J Ophthalmol 1969, 68:263-273.

10- Cohen,JS, Osher ,RH: Releasable scleral flap suture. Ophthalmol Clin North Am 1988;1:187-197.

11- Shin DH: Removable-suture closure of the lamellar scleral flap in trabeculectomy. Ann Ophthalmol 1987;19:51-55.

12- Kobayashi ,H, Kobayashi ,K: A comparison of the intraocular pressure lowering effect of adjustable suture versus laser suture lysis for trabeculectomy. J Glaucoma 2011, 20:228-233.

13- Aykan ,U, Bilge, AH, Akin, T, etal: Laser suture lysis or releasable

sutures after trabeculectomy. J Glaucoma 2007, 16:240-245.

14- Kumari,R, Badhu,B, P, Das,H,: Effectiveness of combination of permanent and releasable scleral flap sutures in trabeculectomy: a randomized clinical trial. Kathmandu Univ Med J (KUMJ). Oct-Dec 2006;4(4):419-25.

15-Watkins PH Jr, Brubaker RF: Comparison of partialthickness and full-thickness filtration procedures in openangle glaucoma. Am J Ophthalmol 1978; 86:756-761.

16- Gross RL: Clinical Glaucoma Management: Critical Signs in Diagnosis and Therapy 1st ed. Philadelphia, Saunders, 2001.

17- Bertrand,V Fieuws,S Ingeborg Stalmans,I,etal: Rates of visual field loss before and after trabeculectomy. Acta Ophthalmol. 2014: 92: 116-120

18- Melamed, S., Ashkenazi, I., Glovinski, J.,etal :Tight Scleral Flap Trabeculectomy With Postoperative Laser Suture Lysis American Journal of Ophthalmology 109:303-309, March, 1990

19-Wells AP, Bunce C, Khaw PT. Flap and suture manipulation after trabeculectomy with adjustable sutures: titration of flow and intraocular pressure in guarded filtration surgery. J Glaucoma 2004; 13:400-406.

20-Unlu K, Aksunger A, Soker S, Ertem M: Mitomycin C primary trabeculectomy with releasable sutures in primary glaucoma. Jpn J Ophthalmol 2000, 44:524-529.

21- Cohen JS, Osher RH. Endophthalmitis associated with releasable sutures. Arch Ophthalmol 1997; 115: 292.

22-Raina UK, Tuli D. Trabeculectomy with releasable sutures: A prospective, randomized pilot study. Arch Ophthalmol. 1998;116(10):1288-1293.

23-Heijl A, Bengtsson B, Hyman L \& Leske MC (2009): Natural history of open-angle glaucoma. Early Manifest Glaucoma Trial Group. Ophthalmology 116: 2271-2276.

\section{ACKNOWLEDGMENT}

SPECIAL THANKS FOR PROF OSAMA RASLAN FOR HIS SUPPORT AND THE GIVEN TRAINING.

CLINICALTRIALS.GOV IDENTIFIER: NCT04651231

Funding: None 